Provided for non-commercial research and education use. Not for reproduction, distribution or commercial use.

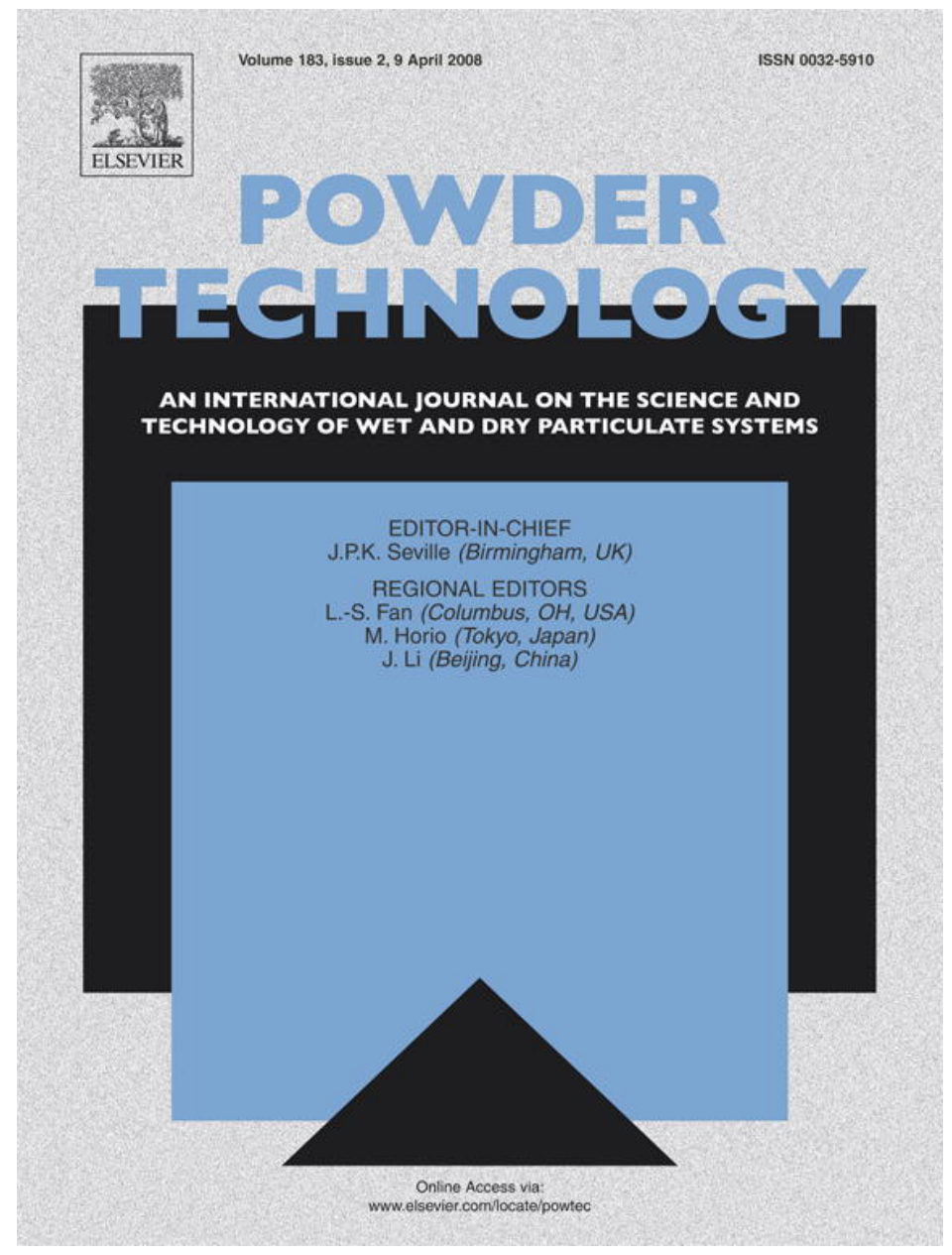

This article was published in an Elsevier journal. The attached copy

is furnished to the author for non-commercial research and education use, including for instruction at the author's institution, sharing with colleagues and providing to institution administration.

Other uses, including reproduction and distribution, or selling or licensing copies, or posting to personal, institutional or third party websites are prohibited.

In most cases authors are permitted to post their version of the article (e.g. in Word or Tex form) to their personal website or institutional repository. Authors requiring further information regarding Elsevier's archiving and manuscript policies are encouraged to visit: 


\title{
Evaluation of flocs resistance and reflocculation capacity using the LDS technique
}

\author{
M.G. Rasteiro ${ }^{\text {a,* }}$, F.A.P. Garcia ${ }^{\text {a }}$, P. Ferreira ${ }^{\text {a }}$, A. Blanco ${ }^{\text {b }}$, C. Negro ${ }^{\text {b }}$, E. Antunes ${ }^{\text {a }}$ \\ ${ }^{a}$ Chemical Engineering Department, Coimbra University, Pólo II, 3030-790 Coimbra, Portugal \\ ${ }^{\mathrm{b}}$ Chemical Engineering Department, Faculty of Chemistry, Complutense University, 28040 Madrid, Spain
}

Received 10 January 2007; received in revised form 28 May 2007; accepted 23 July 2007

Available online 1 August 2007

\begin{abstract}
In a previous paper we have shown the added value of using LDS to monitor flocculation. It can supply, simultaneously, information on flocs size and structure and enlighten flocculation kinetics and mechanisms. In this paper, LDS is applied to study deflocculation and reflocculation processes of precipitated calcium carbonate (PCC) induced by cationic polyacrylamides, when different types of shear forces are applied. LDS can detect the influence of polymer characteristics and concentration as well as of the type of shearing, on flocs resistance and reflocculation degree, which depend on flocs structure and on the type of bonds between particles. As expected, flocs formed by bridging mechanism reflocculate with difficulty while flocs formed by patching reflocculate to a higher degree. Flocs resulting from reflocculation are more compact than the original ones, as assessed by the mass fractal dimension. Reflocculation is also lower when the flocs are submitted to superficial shearing than when they are submitted to sonication. Shearing induced by sonication is sufficient to break down the flocs in many fragments while the increase of pump speed only detaches particles by erosion, at the flocs surface, where bonds are weaker. Results prove that LDS is useful to monitor deflocculation and reflocculation processes and to predict floc resistance under different conditions. Moreover, the whole study demonstrates the benefit of using LDS for a complete evaluation of flocculants performance in the different stages of flocculation: aggregation, stabilization, deflocculation and reflocculation.

(C) 2007 Elsevier B.V. All rights reserved.
\end{abstract}

Keywords: Floc resistance; Light diffraction spectroscopy (LDS); Mass fractal dimension; Reflocculation; Polyelectrolytes

\section{Introduction}

In many industrial processes, flocculated suspensions are subjected to high shear forces (more than $1000 \mathrm{~s}^{-1}$ ) e.g. in the wet end of a paper machine where turbulence is high to favour the uniform formation of the paper sheet [1]. Under these shear conditions, the initial flocs are usually broken up but the suspension partially reflocculates when the shear forces decrease [2]. In these situations, it is not only the flocculation process but also the dynamics and degree of the reflocculation process that depend on the polymer characteristics. Indeed, initial floc properties, mainly size and structure, which are conditioned by the course of aggregation, play a crucial role on the reflocculation stage [3]. Since, the final reflocculation stage determines the behaviour of the suspension in process equipment, the fundamental understanding of both the floccu-

\footnotetext{
* Corresponding author. Tel.: +351 239798700; fax: +351 239798703.

E-mail address: mgr@eq.uc.pt (M.G. Rasteiro).
}

lation and reflocculation processes will greatly benefit the control and optimization of industrial processes.

Tang et al. [4] found that the mechanical strength of the floc depends on both the interparticle forces and on how the particles are packed within the aggregate. The stronger the bonding forces between the particles the higher the floc strength. Similarly, the more compact the floc structure is, the higher the number of interparticle bonds and thus stronger flocs are obtained [3]. So, the strength of flocs depends on the nature of the interaction between particles and on the floc density.

In general, the rupture of a floc is classified as either "surface erosion" or "large-scale fragmentation". Erosion is the separation of small particles from the floc surface, whereas fragmentation refers to the break-up of flocs into pieces of comparable size. Theoretical models in the literature have attributed particle erosion to shearing stresses on the floc surface, while fragmentation is thought to be caused by pressure gradients across the entire body [5]. It is also well reported in the literature that the flocs formed using polyelectrolytes are 
reformed after being broken up but do not regain their original size and structure except if neutralisation is the main flocculation mechanism $[6,7]$. This is due to different causes depending on the predominant flocculation mechanism, for example, to the detachment of polymer chains from particles resulting in polymer degradation. Thus, the original bonds are not able to reform to their previous extent reducing the efficiency of aggregation between fragments of flocs. Since flocs break-up occurs at the weakest point in the floc structure, this results normally in more compact aggregates, though smaller than the initial flocs. When the flocs reform partially, the new structure is compacted to denser forms by shear-induced reorganization [6], and mass fractal dimension must be higher due to restructuring of the reformed flocs.

Reflocculation efficiency depends on the polymer type. Indeed, flocs induced by bridging mechanism are stronger than flocs induced by patching but the stronger the flocs are initially the more difficult is reflocculation when the aggregate breaks [1]. In fact, when the shear force increases the tails and loops of high molecular polymers are broken and, therefore, when the shear force decreases thereafter the possibility of reflocculation by bridging decreases and reflocculation takes place rather through the patch mechanism $[1,8]$. In the case of patching, the effect of shear forces on the polymer is lower but if the polymer is re-conformed within the diffuse layer the interactions with other particles will decrease so, reflocculation, though easier, may be also lower than the original flocculation degree [9].

Though many studies have been presented in the literature about flocculation by polyelectrolytes, the experimental strategy is usually either directed at the flocculation stage $[10,11]$ or at the reflocculation one $[8,12,13]$ or even at evaluating flocs resistance through another separate test $[5,14,15]$. Blanco et al. have developed a methodology to study flocculation and reflocculation based on the particle chord evolution [7]. However, the added value of using LDS is that the three aspects can be evaluated in a single test, with the possibility of correlating flocs resistance with floc structure, as will be shown in the present paper.

In a companion paper [16] we have shown the advantage of LDS to monitor flocculation processes and to evaluate the flocs characteristics because it allows acquisition, in a single test, of information about flocculation kinetics, flocs average size and size distribution and flocs structure, based on the mass fractal dimension.

The LDS technique is based on the relation that can be established between the scattering angle and the size of the particles [17]. From the raw signal obtained one can extract information on the particle size distribution of the sample, based either on the Fraunhofer or on the Lorenz Mie theory [18], and on the fractal dimension of the aggregates. The fractal dimension supplies information about the density of the aggregates and, according to the Rayleigh-Gans-Debye theory, can be calculated from the negative slope of $\log -\log$ plot of the scattered light intensity as a function of the wave number vector [19].

In this paper, the use of the light diffraction spectroscopy (LDS) technique is extended in order to evaluate the deflocculation and reflocculation processes, when flocs are submitted either to sonication with different frequencies (mechanical forces) or to an increase of the shear forces in the recirculation tubes of the test equipment (hydrodynamic shearing) by increasing the pump speed. An assessment of flocs resistance and reflocculation capacity in both cases has also been carried out.

Flocculation of precipitated calcium carbonate (PCC) was carried out using high molecular weight cationic polyacrylamides (CPAM) with different charge densities. In this way, the effect of charge density and the effect of flocculant concentration on flocs resistance and on their reflocculation ability were investigated.

With this paper we have extended further the work aimed at optimizing the use of LDS to monitor flocculation processes in an integrated way, including assessment of flocs resistance and reflocculation capacity. The main limitation of this methodology lies in the maximum solids concentration that can be used in the measurements, always below $0.02 \%(\mathrm{v} / \mathrm{v})$.

\section{Experimental}

\subsection{Materials}

Industrial PCC was used in the flocculation experiments. The PCC was dried before use to obtain a dry powder. PCC suspensions were prepared at $1 \%(\mathrm{w} / \mathrm{w})$ in distilled water and, to obtain a good dispersion of the particles, the suspension was firstly agitated using magnetic stirring at $600 \mathrm{rpm}$ during $40 \mathrm{~min}$ and then submitted to sonication at $50 \mathrm{kHz}$ during $15 \mathrm{~min}$. The $\mathrm{pH}$ of the PCC suspension in these conditions was 7.5 and the median size of the particles was $0.5 \mu \mathrm{m}$.

The two flocculants used in this study were CPAMs of high molecular weight with different charge density and lightly branched. The first one, Alpine-Floc ${ }^{\mathrm{TM}}$ BHMW, has got a linear chain with a molecular weight around $7.2 \cdot 10^{6} \mathrm{~g} / \mathrm{mol}$ and with a high cationic charge density $(80 \%(\mathrm{w} / \mathrm{w})$ of the groups are charged) and the second one, Alpine-Floc ${ }^{\mathrm{TM}} \mathrm{E} 1+$, has got one branch per molecule with a molecular weight of $13 \cdot 10^{6} \mathrm{~g} / \mathrm{mol}$ and $50 \%(\mathrm{w} / \mathrm{w})$ of the groups charged. The cationic monomer in the polymers is dimethylamino ethyl acrylate. Both polymers were supplied by AQUA+TECH Specialties S.A. The stock solution of BHMW was diluted to $0.05 \%$ and, in the case of $\mathrm{E} 1+$, to $0.1 \%$. These dilutions were prepared daily. The water conductivity was also controlled and kept between 5 to $8 \mu \mathrm{S}$ / $\mathrm{cm}$ to avoid variations on the flocculation process.

\subsection{Methods}

PCC flocculation was monitored by measuring the aggregates sizes by LDS using a Malvern Masterziser 2000 (Malvern Instruments). The PCC suspension was added to $700 \mathrm{~mL}$ of distilled water in the equipment dispersion unit until $30 \%$ obscuration (average PCC concentration around $0.02 \%(\mathrm{w} / \mathrm{w})$ ) and the tests were carried out setting the pump speed to $1400 \mathrm{rpm}\left(663 \mathrm{~s}^{-1}\right)$. Obscuration was always kept above $5 \%$ to assure a good signal quality $[16,20]$. Ideally, obscuration should be below 20\%. However, as obscuration decreases during the flocculation test due to floc growth, we have decided to initiate the tests with an obscuration of $30 \%$ to guarantee that, at the end of flocculation, obscuration is always higher than $5 \%$. 
Table 1

Mass fractal dimension values at the end of flocculation and after $5 \mathrm{~min}$ of the reflocculation processes using BHMW

\begin{tabular}{llllll}
\hline $\begin{array}{l}\text { Concentration } \\
(\mathrm{mg} / \mathrm{g})\end{array}$ & \multicolumn{5}{l}{ Mass fractal dimension } \\
\cline { 2 - 6 } & End of flocculation & $5 \mathrm{~min}$ of reflocculation & \\
\cline { 2 - 6 } & & $10 \mathrm{kHz}$ & $20 \mathrm{kHz}$ & $1800 \mathrm{rpm}$ & $2200 \mathrm{rpm}$ \\
\hline 2 & 1.63 & 1.72 & 1.71 & 1.67 & 1.70 \\
6 & 1.38 & 1.59 & 1.65 & 1.45 & 1.44 \\
10 & 1.46 & 1.54 & 1.58 & 1.37 & 1.41 \\
14 & 1.58 & 1.59 & 1.57 & 1.44 & 1.47 \\
\hline
\end{tabular}

The two flocculants were tested for a range of concentrations, close to the optimum dosage. The optimum flocculant dosage was firstly determined performing the test according to Blanco's methodology [21], as has been already published [16].

The particle size of PCC was always measured before adding the flocculant to the suspension. After that, a fixed predetermined amount of flocculant was added at once to the suspension and the flocs size distribution was measured every minute during $14 \mathrm{~min}$, i.e., till the flocs size seemed to stabilize.

This technique allows one to monitor also the mass fractal dimension of flocs during the tests. This parameter was calculated from the scattering pattern used to determine the particle size, according to the Rayleigh-Gans-Debye theory, since the primary particle size was around $0.5 \mu \mathrm{m}$ with a refractive index of 1.572 [16,22].

The floc resistance evaluation was performed using two different types of shear forces. The first approach was to submit the flocs to sonication at two different frequencies during 30 seconds: $10 \mathrm{kHz}$ and $20 \mathrm{kHz}$. This mechanical shear force was directly applied to the suspension in the LDS dispersion unit, after flocculation. The second method involved the application of different hydrodynamic shear forces during one minute by increasing the recirculating peristaltic pump speed from $1400 \mathrm{rpm}$ first to $1800 \mathrm{rpm}$ and then to $2200 \mathrm{rpm}$, which corresponds to increasing the shear rate in the flow tubes from $663 \mathrm{~s}^{-1}$ to $1125 \mathrm{~s}^{-1}$ and to $1686 \mathrm{~s}^{-1}$, respectively. After both shearing tests, the shear force was restored to the initial value to allow the reflocculation process to take place, which was monitored during $14 \mathrm{~min}$.

\section{Results and discussion}

In a previous work [16] LDS was used to study PCC flocculation mechanisms induced by BHMW and E1+. In that paper we show that, for the materials studied, the average floc size obtained by LDS is similar to the one retrieved by optical microscopy. It was possible to observe that the flocculation mechanism depends on the charge density and on the concentration of the flocculant. In this case, the optimum flocculant dosage was found to be $10 \mathrm{mg} / \mathrm{g}$ for BHMW and $15 \mathrm{mg} / \mathrm{g}$ for E1+, if the final median flocs size is taken as the optimization parameter. Initial flocculation with BHMW was the result of a combination of bridging and patching mechanisms. The predominance of the patching mechanism increased with the flocculant concentration. In the case of the flocs formed with E1+, only the bridging mechanism occurred. The occurrence of patching mechanisms depends on the molecular weight and charge density of the polymer. In some cases, the flocs size can decrease after reaching a maximum due to re-conformation of the polymer chain on the particles surface and/or to break-up of the flocs formed. Depending on the flocculation mechanism that takes place, the floc structure at the end of the flocculation process varies. So, the resistance of flocs, which is strongly dependent on flocs structure, will also be conditioned by the charge density of the polymer and by the flocculant concentration.

The floc structure at the end of the flocculation process can be described by the mass fractal dimension which is shown in Tables 1 and 2 for the two polymers. We concluded in a companion publication [16] that flocs obtained with BHMW are more compact than the ones obtained with E1+, since they exhibit higher mass fractal dimension values that increase with flocculant concentration.

The results of the different shearing tests conducted after the flocculation stage will be discussed next. We have calculated the percentage of flocs break-up as the ratio of the difference between the initial and final flocs size after shearing and the size of the flocs at the end of flocculation.

\subsection{Effect of sonication}

When the flocs are submitted to sonication, their size rapidly decreases as shown in Figs. 1 and 2. Breakage of flocs indicates that the polymer chains detach from the particles surface resulting on rupture of bonds between the particles in the aggregate. Tables 3 and 4 show that break-up of flocs is higher as the applied sonication frequency increases, since the shear forces increased. It is observed that flocs produced with BHMW are more resistant to sonication than those obtained with E1+. In fact, break-up percentages are higher for $\mathrm{E} 1+$, even for low sonication frequencies, which may be due, on one hand, to the larger size of the flocs and, on the other, to the low reflocculation ability of the sample due to steric repulsion and polymer degradation and flattening. These results agree with the mass fractal dimension values observed at the end of the flocculation process (see Tables 1 and 2) which show that flocs produced with BHMW are denser than those produced with E1+.

Although it should be expected that flocs produced with BHMW would be softer, due to the patching mechanism, they are more resistant because of the packing structure of the particles within the aggregate [3] and still able to reflocculate. On the other hand, the reduction of flocs size, due to sonication, is higher as the flocculant concentration increased. This means

Table 2

Mass fractal dimension values at the end of flocculation and after $5 \mathrm{~min}$ of the reflocculation processes using E1+

\begin{tabular}{llllll}
\hline \multirow{2}{*}{$\begin{array}{l}\text { Concentration } \\
(\mathrm{mg} / \mathrm{g})\end{array}$} & \multicolumn{5}{l}{ Mass fractal dimension } \\
\cline { 2 - 6 } & End of flocculation & $5 \mathrm{~min}$ of reflocculation & \\
\cline { 3 - 6 } & & $10 \mathrm{kHz}$ & $20 \mathrm{kHz}$ & $1800 \mathrm{rpm}$ & $2200 \mathrm{rpm}$ \\
\hline 10 & 1.48 & 1.64 & 1.67 & 1.57 & 1.60 \\
15 & 1.38 & 1.57 & 1.63 & 1.52 & 1.53 \\
20 & 1.35 & 1.55 & 1.59 & 1.51 & 1.48 \\
25 & 1.36 & 1.55 & 1.60 & 1.48 & 1.47 \\
\hline
\end{tabular}




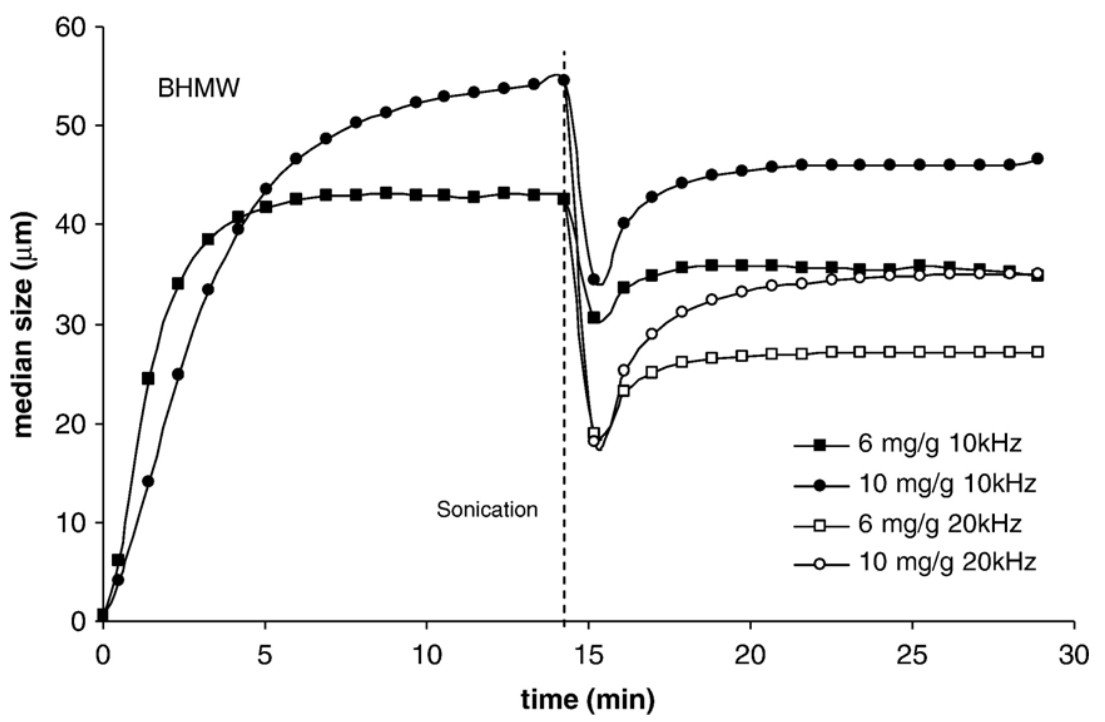

Fig. 1. Flocculation with BHMW, deflocculation and reflocculation after sonication.

that despite being bigger and more compact $\left(d_{\mathrm{F}}\right.$ increases with flocculant concentration), flocs are less resistant as the flocculant concentration increases. As we have seen before [16], in this case, due to the high charge density of the polymer, the patching bonds predominate as the flocculant concentration increases and, therefore, flocs are less resistant to shear forces. It is known that flocs formed by patching are less resistant than those formed by bridging. On the other hand, at the end of flocculation, for lower flocculant concentration, the same polymer chain has the opportunity to be adsorbed at the particle surface in several sites, while for higher flocculant concentration, because the number of polymer chains adsorbed at the particle surface is higher, single polymer chains are linked to fewer particle sites. For these reasons, the polymer is much more strongly attached to the particles for lower concentrations, resulting in stronger flocs. Furthermore, floc size increases with dosage, enhancing their sensibility to shear forces.
The break-up, by sonication, of the flocs formed with E1+ is not much dependent on the flocculant concentration, as shown in Fig. 2 and by the values of $d_{\mathrm{F}}$, at the end of flocculation (Table 2), in agreement with the fact that the flocculation mechanism does not change with flocculant concentration. However, by observing the results shown in Table 4, break-up percentage seems to go through a maximum that coincides with the maximum floc size at the end of the flocculation stage, reached for the optimum flocculant concentration $(15 \mathrm{mg} / \mathrm{g})$. In fact, when flocs size decreases, with excess polymer, resistance increases again because the shear forces are less efficient. So, as found by Blanco et al. [8], a moderate excess of polymer can improve the floc strength.

The reflocculation degree is, in general, higher for flocs obtained with BHMW (Tables 3 and 4) as expected from the patching mechanism. In fact, we have seen that the predominant flocculation mechanism with E1+ is by bridging. These flocs, when broken, allow the re-conformation of the polymer, which no longer regains

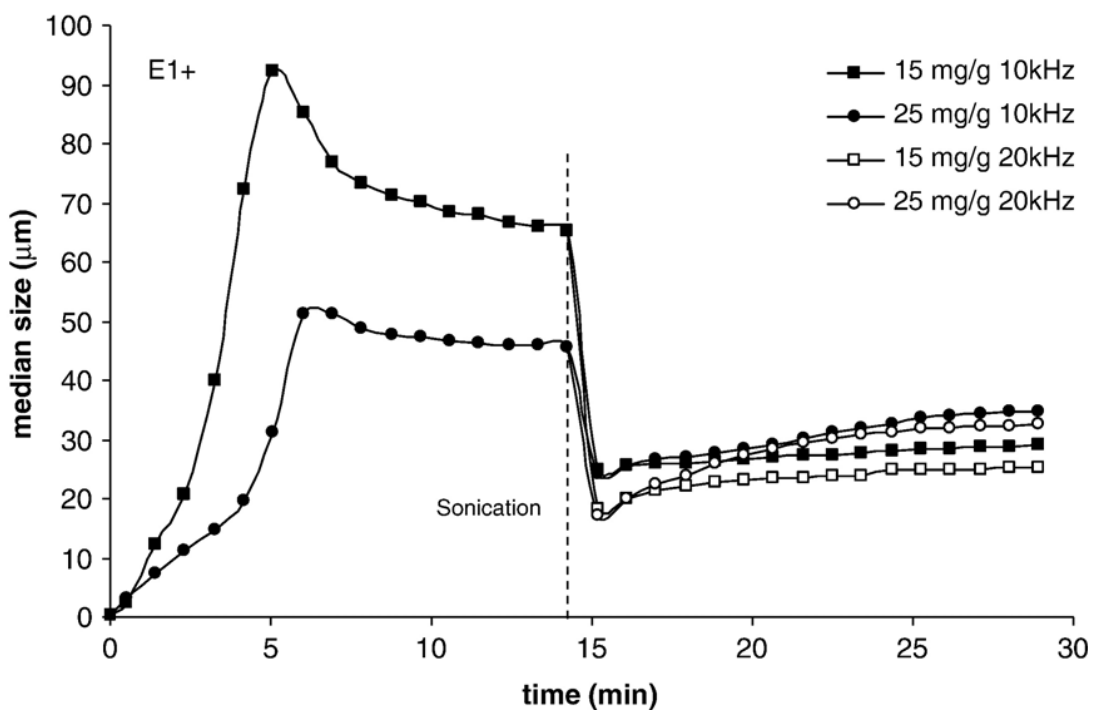

Fig. 2. Flocculation with E1+, deflocculation and reflocculation after sonication. 
Table 3

Break-up and reflocculation percentages using BHMW

\begin{tabular}{|c|c|c|c|c|c|c|c|c|}
\hline \multirow[t]{2}{*}{ Concentration (mg/g) } & \multicolumn{4}{|c|}{ Break-up (\%) } & \multicolumn{4}{|c|}{ Reflocculation after 5 min (\%) } \\
\hline & $10 \mathrm{kHz}$ & $20 \mathrm{kHz}$ & $1800 \mathrm{rpm}$ & $2200 \mathrm{rpm}$ & $10 \mathrm{kHz}$ & $20 \mathrm{kHz}$ & $1800 \mathrm{rpm}$ & $2200 \mathrm{rpm}$ \\
\hline 2 & 14 & 33 & 2 & 12 & 5 & 25 & -1 & -2 \\
\hline 6 & 28 & 57 & 6 & 17 & 18 & 41 & -1 & 5 \\
\hline 10 & 37 & 67 & 8 & 20 & 32 & 83 & 2 & 12 \\
\hline 14 & 37 & 65 & 9 & 22 & 41 & 96 & 5 & 13 \\
\hline
\end{tabular}

the same conformation that originated loops and tails and allowed particles aggregation. Therefore, polymer degradation during break-up makes the reflocculation process more difficult. This does not occur with BHMW due to existence of the patching mechanism. This bond type is only partially affected by the shear stress and, thus, these bonds are more easily restored, resulting in a higher reflocculation percentage compared to E1+.

The reflocculation percentage increases as the flocculant concentration increased (see Tables 3 and 4). As we have referred, shear stresses degraded totally flocculation induced by E1+ and partially flocculation induced by BHMW. So, due to flocs fragmentation, free particle surface is created where the excess and not degraded polymer can be again adsorbed, although the reflocculation percentage is low due to steric and electrostatic repulsions. Furthermore, the reflocculation percentage increased as the shear stress during breaking increased, as we can see in Tables 3 and 4, that is when the break-up of flocs is higher. This effect is more notorious in the case of BHMW. Indeed, the number of bonds broken is higher and in this case (BHMW) they are partially re-established by the same mechanism. In the case of $\mathrm{E} 1+$, reflocculation may take place by patching, due to the re-conformation of the polymer chains towards a flat configuration, and by bridging bonds in the case of the excess polymer. In this case, the mass fractal dimension of flocs at $5 \mathrm{~min}$ of the reflocculation stage is higher than at the end of flocculation, as shown in Table 2. This agrees again with the fact that reflocculation occurs predominantly by patching bonds $[1,8]$, leading to a reorganization of particles that originates denser flocs than the original ones where bridging bonds prevailed. In the case of BHMW, the mass fractal dimension of the flocs at $5 \mathrm{~min}$ of reflocculation increases for lower flocculant concentrations, due to the flattening of polymer that increases the density of the flocs. It decreases slightly for higher flocculant concentrations in comparison with the values at the end of the flocculation stage (see Table 1) due to the presence of electrostatic repulsion forces that limit the minimum distance between particles. Furthermore, when the polymer was not in excess, aggregation was faster, patching and bridging bonds coexisted and, thus, reflocculation, due to the low concentration of polymer, only took place through bonds that were partially degraded, leading to particles reorganization that resulted in more compact flocs. When the polymer was in excess, the particles that were initially linked together mainly by patching, could not reorganize so much due to the high molecular weight of the excess polymer. This polymer did not tend to suffer re-conformation and did not degrade easily, so the new polymer chains in the way to adsorb at the particle surface, after break-up, were not able to acquire the same flat conformation due to the lack of space and, thus, a slightly lower value of $d_{\mathrm{F}}$ resulted.

\subsection{Effect of hydrodynamic shearing}

Figs. 3 and 4 show flocculation, deflocculation and reflocculation behaviour when the flocs were submitted to increased hydrodynamic shearing from $663 \mathrm{~s}^{-1}$ to $1125 \mathrm{~s}^{-1}$ and to $1686 \mathrm{~s}^{-1}$, by increasing the recirculating pump speed from $1400 \mathrm{rpm}$ to $1800 \mathrm{rpm}$ and to $2200 \mathrm{rpm}$, respectively. Results obtained for the flocculant concentrations not shown in those figures are summarized on Tables 3 and 4. If we compare Tables 3 and 4 , the flocs size decrease percentage during deflocculation is more or less the same for both polymers. Moreover, this decrease is less notorious than when ultra-sounds are applied. The flocs break-up can occur by two different mechanisms as mentioned before (erosion and fragmentation). For the pump speeds tested, the shear stress at the flocs surface must be the main effect and, thus, the flocs size decrease during deflocculation must be due to flocs erosion. This agrees with the fact that larger flocs showed a higher degree of erosion, as is the case for the optimum concentration of E1+ $(15 \mathrm{mg} / \mathrm{g})$; and with the fact that the effect is similar for both flocculants, since rupture by erosion is not much dependant on the type of bonds established and neither on flocs structure. In reality, what happens is that flocs reach another equilibrium state where aggregation and fragmentation rates are the same. Of course, erosion and, thus, size decrease is higher when the pump speed increased.

Table 4

Break-up and reflocculation percentages using E1+

\begin{tabular}{|c|c|c|c|c|c|c|c|c|}
\hline \multirow[t]{2}{*}{ Concentration (mg/g) } & \multicolumn{4}{|c|}{ Break-up (\%) } & \multicolumn{4}{|c|}{ Reflocculation after $5 \min (\%)$} \\
\hline & $10 \mathrm{kHz}$ & $20 \mathrm{kHz}$ & $1800 \mathrm{rpm}$ & $2200 \mathrm{rpm}$ & $10 \mathrm{kHz}$ & $20 \mathrm{kHz}$ & $1800 \mathrm{rpm}$ & $2200 \mathrm{rpm}$ \\
\hline 10 & 63 & 66 & 5 & 17 & 5 & 20 & -6 & -5 \\
\hline 15 & 60 & 72 & 10 & 20 & 7 & 26 & -4 & -3 \\
\hline 20 & 58 & 66 & 6 & 17 & 11 & 40 & -1 & 1 \\
\hline 25 & 51 & 62 & 6 & 16 & 17 & 58 & 1 & 4 \\
\hline
\end{tabular}




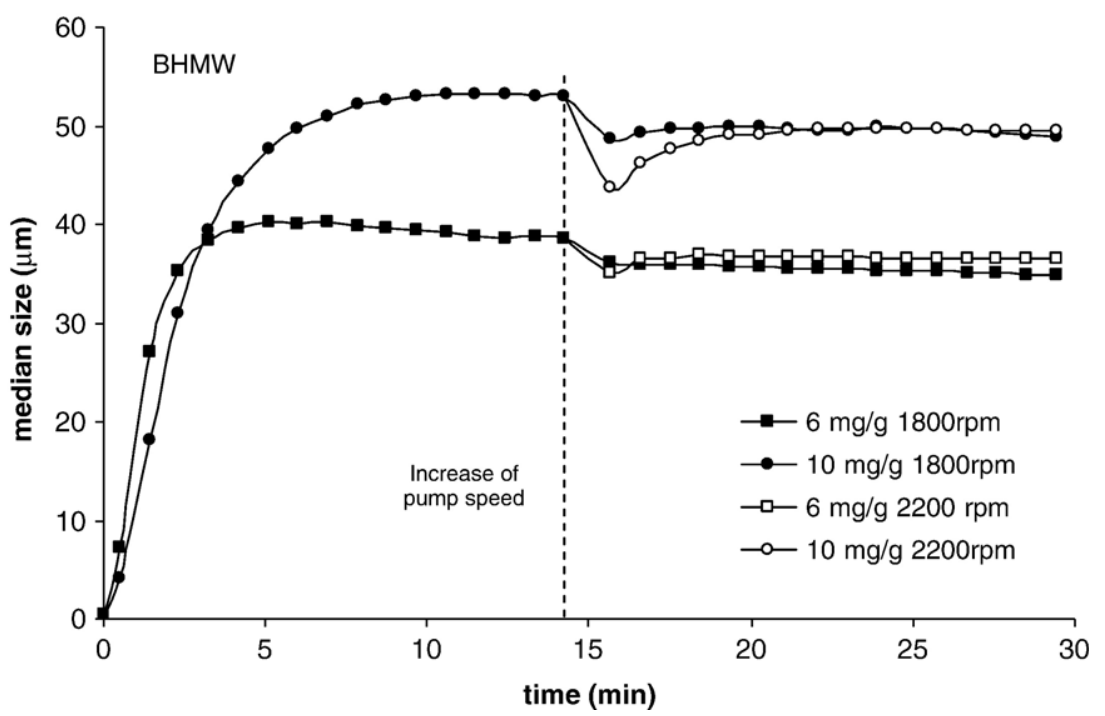

Fig. 3. Flocculation using BHMW, deflocculation and reflocculation as pump speed increases.

For BHMW, despite the very small differences, the break-up percentage increases with flocculant concentration increase (see Table 3). We have seen that the number of patching bonds increases as the flocculant concentration increases and, since this type of bonds is weaker, small particles depart from the flocs surface more readily as the flocculant concentration increases.

For E1+, we have seen there was homogeneity of interparticles bonds which are stronger (bridging bonds) and thus, in this case, erosion did not depend on the flocculant concentration. As a result, erosion increased with pump speed but did not vary significantly with flocculant concentration.

Examining again Tables 3 and 4, for the lower concentrations of the two flocculants, reflocculation did not occur after rupture of the primary flocs. Break-up is not sufficient to induce reflocculation. On the one hand, the restructuring of particles due to shear forces originates flocs which are more compact resulting therefore in slightly smaller flocs. The values of $d_{\mathrm{F}}$ in
Tables 1 and 2 agree with this conclusion. On the other hand, the bonds that break during shearing refer to the detachment of very small particles and do not lead to reflocculation.

For higher flocculant concentrations and for both flocculants, reflocculation occurs due to the excess of polymer, being more notorious when break-up is higher. In fact, in this case, the number of particles free for the reflocculation process is larger. In the case of BHMW, reflocculation is again higher since the patching bonds that break during deflocculation do not result in so much polymer degradation and can, in part, be re-established. The flocs formed are less compact than the initial ones resulting in lower mass fractal dimension values, since, due to the excess polymer, reflocculation can also occur by bridging. The flocs become less compact despite the restructuring effect of particles during superficial shearing. In the case of E1+, reflocculation is not so notorious except for the highest concentration for the reasons mentioned above. Thus, there was mainly a compaction

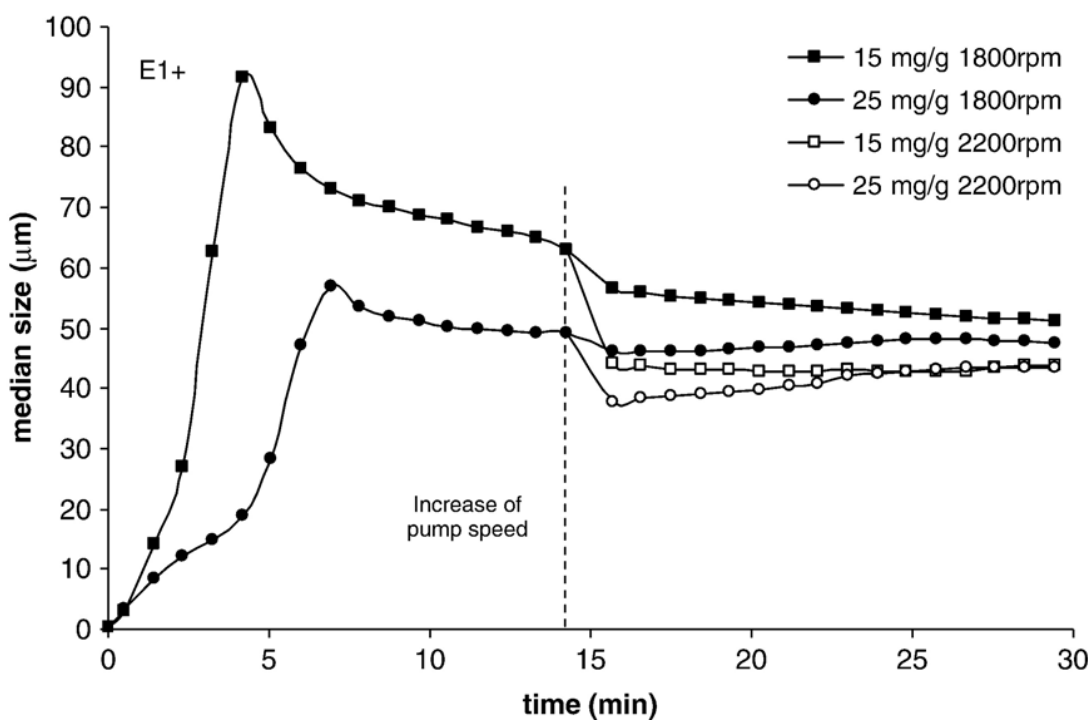

Fig. 4. Flocculation using E1+, deflocculation and reflocculation as pump speed increases. 
of the flocs due to the superficial restructuring of the particles and the mass fractal dimension, at $5 \mathrm{~min}$ of reflocculation, is higher. Re-conformation of polymer chains during this process can also contribute to the increase of the mass fractal dimension.

\subsection{Comparison of sonication and pump speed effects}

If we compare the results of Tables 3 and 4, we observe that flocs breakage is more pronounced when the flocs were submitted to sonication. This is due to the way how the shearing force was applied. When the flocs were submitted to sonication the stresses were applied to the entire floc resulting in rupture by fragmentation, while the increase of the pump speed corresponded to a shear stress applied at the flocs surface only and, thus, flocs rupture occurred by erosion. In the first case, break-up resulted in many small aggregates that could easily reflocculate, leading to higher percentage of reflocculation. In the second case, fewer bonds were broken, since only a few particles were detached from the flocs surface, resulting in a lower reflocculation percentage as shown. Nevertheless, both tests can be very useful to evaluate flocs resistance. The first one, sonication, supplies information on intrinsic flocs resistance, important for instance, to predict flocs behaviour in highly turbulent environments like mixing tanks or the headbox of a paper machine. The second one, supplies information on flocs resistance to hydrodynamic superficial shearing, corresponding to conditions similar to those prevailing when a flocculated suspension is conveyed in a pipe (shear rates around $1000 \mathrm{~s}^{-1}$ as mentioned previously).

\section{Conclusions}

This paper is a step further in the evaluation of the usefulness and added value of LDS to monitor flocculation processes and evaluate the performance of polymeric flocculants.

In a companion paper we have proved that LDS can be used to supply, in a single integrated test, information on the time evolution of the average flocs size and size distribution, flocs structure and flocculation kinetics. In that paper it has been shown that the average diameter obtained by LDS was similar to the one retrieved by optical microscopy. Microscopy presents, nevertheless, several drawbacks, the main one being the difficulty of sample preparation. The preparation stage can, very easily, lead to deterioration of the aggregates.

Here, LDS has been successfully applied to study, in the same single test, the flocculation, deflocculation and reflocculation processes of a PCC suspension, when flocs were submitted either to sonication or to an increase of the hydrodynamic shearing. These two tests supply information on flocs resistance in two different situations that can be found in process equipment: (i) intrinsic flocs resistance of importance when the flocs are submitted to highly turbulent environments, and (ii) superficial flocs resistance important when flocs are conveyed in pipes and ducts.

LDS data allow us to observe the influence of polymer characteristics and concentration as well as the type of shearing on flocs resistance and reflocculation degree. Floc resistance has been correlated with flocs structure, based on mass fractal dimension data.
The effect of sonication or hydrodynamic shearing was very different. Sonication produces a high deflocculation and reflocculation effect which depends on the flocs size and flocculation mechanism, while the effect of hydrodynamic shearing was due to erosion, being low and similar for the two polymers studied. Results show that flocs formed by bridging mechanism reflocculate with difficulty while flocs formed by patching reflocculate to a higher degree. Flocs resulting from the reflocculation process are, in general, more compact than the original ones. It was possible to relate floc structure at the end of the reflocculation stage with the bonding mechanisms prevailing during that stage, which are dependent on the flocculant characteristics and concentration.

The results presented refer only to the flocculation of calcium carbonate which is used as filler in papermaking. These results are a good example of the application of LDS to a process where the break-up of flocs by different mechanisms can be important. However, the methodology presented can be easily applied to other flocculation systems to evaluate and predict flocculants performance, by monitoring the flocculation process and predicting several floc characteristics in an integrated way (single test). The main limitation of this methodology lies in the maximum solids concentration that can be used, which, nevertheless, is a weakness common to several particle size measurement techniques.

\section{Acknowledgements}

The authors thank the European Project Nodeszeloss for financial support and AQUA+TECH Specialties S.A. (La Plaine, Geneva, Switzerland) for supplying the flocculants samples.

\section{References}

[1] M. Norell, J. Kjell, M. Persson, Retention and Drainage, Papermaking and Science Technology, Book 4: Papermaking Chemistry, L. Neimo, Finland, 1999, pp. 42-61.

[2] S. Yoon, Y. Deng, Flocculation and reflocculation of clay suspension by different polymer systems under turbulent conditions, J. Colloid Interface Sci. 278 (2004) 139-145.

[3] M. Hermawan, T. Yang, G. Bushell, R. Amal, G. Bickert, A new approach in determining floc strength, Part. Syst. Analysis (2003) (Harrogate, UK).

[4] S. Tang, Y. Ma, C. Shiu, Modelling the mechanical strength of fractal aggregates, Colloids Surf., A Physicochem. Eng. Asp. 180 (2001) 7-16.

[5] A.K.C. Yeung, R. Pelton, Micromechanics: a new approach to studying the strength and breakup of flocs, J. Colloid Interface Sci. 184 (1996) 579-585.

[6] P.T. Spicer, S. Pratsinis, J. Raper, R. Amal, G. Bushell, G. Meesters, Effect of shear schedule on particle size, density, and structure during flocculation in stirred tanks, Powder Technol. 97 (1998) 26-34.

[7] A. Blanco, E. Fuente, C. Negro, J. Tijero, Flocculation monitoring: focussed beam reflectance measurement as a measurement tool, Can. J. Chem. Eng. 80 (2002) 734-740.

[8] A. Blanco, C. Negro, E. Fuente, J. Tijero, Effect of shearing forces and flocculant overdose on filler flocculation mechanisms and floc properties, Ind. Eng. Chem. Res. 44 (2005) 9105-9112.

[9] A. Blanco, E. Fuente, C. Negro, C. Monte, J. Tijero, Focused beam reflectance measurement as a tool to measure flocculation, Tappi J. 1 (10) (2002) 14-20.

[10] T.N. Prabhu, T.J. Rao, K. Prashantha, Studies on flocculation of clay suspension by polyacrylamide, e-Polymers 57 (2004).

[11] D. Solberg, L. Wagberg, Adsorption and flocculation behaviour of cationic polyacrylamide and colloidal silica, Colloids Surf., A Physicochem. Eng. Asp. 219 (2003) 161-172. 
[12] M.A. Yukselen, J. Gregory, The reversibility of floc breakage, Int. J. Miner. Process. 73 (2004) 251-259.

[13] J.C. Alfano, P.W. Carter, A.J. Dunham, M.J. Nowak, K.R. Tubergen, Polyelectrolyte-induced aggregation of microcrystalline cellulose: reversibility and shear effects, J. Colloid Interface Sci. 223 (2000) 244-254.

[14] S.R. Gray, C.B. Ritchie, Effect of organic polyelectrolyte characteristics on floc strength, Colloids Surf., A Physicochem. Eng. Asp. 273 (2006) 184-188.

[15] R.K. Chakraborti, K.H. Gardner, J.F. Atkinson, J.E. Van Benschoten, Changes in fractal dimension during aggregation, Water Res. 37 (2003) 873-883.

[16] M.G. Rasteiro, F.A.P. Garcia, P. Ferreira, C. Negro, A. Blanco, E. Antunes., in press. The use of LDS as a tool to evaluate flocculation mechanisms, Chem. Eng. Process. (doi:10.1016/j.cep.2007.04.009).

[17] ISO 13320-1 Particle Size Analysis-Laser Diffraction Methods. Part 1: General Principle, International Organization of Standardization, Genève, 1999.
[18] G.B.J. De Boer, C. de Weerd, D. Thoenes, H.W.J. Goossens, Laser diffraction spectroscopy: Fraunhofer diffraction versus Mie scattering, Part. Charact. 4 (1987) 14-19.

[19] J. Teixeira, Small-angle scattering by fractal systems, J. Appl. Crystallogr. 21 (1988) 781-785.

[20] M.G. Rasteiro, F. Garcia, M. del Mar Peréz., in press. Applying LDS to monitor flocculation in papermaking, Part. Sci. Technol. 25.

[21] A. Blanco, C. Negro, A. Hooimeijer, J. Tijero, Polymer optimization in paper mills by means of a particle size analyser: an alternative to zeta potential measurements, Appita J. 49 (1996) 113-116.

[22] J.Y.H. Liao, C. Selomulya, G. Bushell, G. Bickert, R. Amal, On different approaches to estimate the mass fractal dimension of coal aggregates, Part. Part. Syst. Charact. 22 (2005) 299-309. 